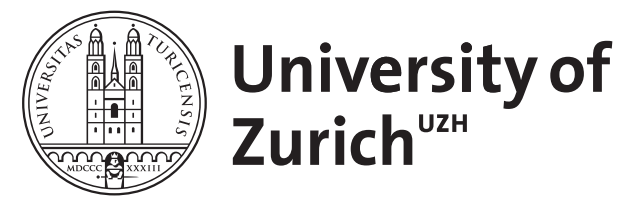

Zurich Open Repository and Archive

University of Zurich

University Library

Strickhofstrasse 39

CH-8057 Zurich

www.zora.uzh.ch

Year: 1989

\title{
Geschichtskonzepte im Ezechielbuch
}

Krüger, Thomas

Posted at the Zurich Open Repository and Archive, University of Zurich

ZORA URL: https://doi.org/10.5167/uzh-50145

Monograph

Published Version

Originally published at:

Krüger, Thomas (1989). Geschichtskonzepte im Ezechielbuch. Berlin: De Gruyter. 
IBR-Online

Internationale Bibliographie der Rezensionen geistes- und sozialwissenschaftlicher Literatur International Bibliography of Book Reviews of Schorlarly Literature in the Humanities and Social Sciences

Rezensent: köckert, matthias

Autor: krüger, thomas

Rezension von: geschichtskonzepte im ezechielbuch. berlin, new york: de gruyter. 1989. XI, 524 s., $178 \mathrm{dm}$. (bzaw 180).

Zeitschrift: theologische literaturzeitung. monatsschrift für das gesamte gebiet der theologie und religionswissenschaft

Band: 116

Nummer: 12

Seite(n): $900-903$

Erscheinungsjahr: 1991

Verlag: evangelische verlagsanstalt gmbh, leipzig

ISSN: $0040-5671$

Sprache (Artikel): Deutsch

Sachgebiet (Artikel): Philosophie, Theologie, Psychologie

Schlagwörter: hesekiel (prophet)altes testamentprophetezechielold testamentezekiel (prophet)

Gs.F.X

00

\section{Zugang bereitgestellt von: UZH Hauptbibliothek / Zentralbibliothek Zürich}

Copyright $\odot$ 2011-2017 by Walter de Gruyter GmbH

Powered by PubFactory 